\title{
Socio-Demographic Correlates in Patients with First Episode Depression in a Tertiary Hospital
}

\author{
Saraswati Dhungana, ' Saroj Prasad Ojha, ${ }^{1}$ Manisha Chapagain, ${ }^{1}$ Pratikchya Tulachan ${ }^{1}$ \\ 'Department of Psychiatry and Mental Health, Maharajgunj Medical Campus, Tribhuvan University Teaching Hospital, \\ Kathmandu, Nepal.
}

\section{ABSTRACT}

Introduction: Depression is the most chronic mental illness that afflicts mankind. It is widely believed to be the disease affecting mainly female gender, economically disadvantaged group with low level of education and those residing in the urban setup. There are only few studies looking into the sociodemographic correlates of depression in the context of Nepal.

Methods: We looked at 70 patients with new-onset depression who met the criteria for diagnosis of depression as per ICD-10 DCR. A self- designed semi- structured proforma was developed to obtain the socio-demographic variables and was filled in the OPD and the data were analyzed.

Results: Mean age of the patients was $30.30 \pm 9.75$ years and $70 \%$ of the patients were females. There were almost equal number of patients residing in and out of Kathmandu valley. Most of the patients had attained secondary level of education and were married, housewives and belonged to nuclear family. Majority were Hindus, Brahmins, and from middle class family.

Conclusions: We found that patients with first episode depression were relatively young with female predominance most attaining at least secondary level of education; and most belonging to middle class nuclear families.

Keywords: depression; ICD-10 DCR; socio-demographic correlates.

\section{INTRODUCTION}

Depression is a significant contributor to the global burden of disease and affects people in all communities across the world. $^{1}$ According to the World Health Organization, unipolar depressive disorders were ranked as the third leading cause of the global burden of disease in 2004 and will move into the first place by $2030 .{ }^{2}$ Its high prevalence, onset in the productive age group and tendency for recurrence makes it a major public health problem. The most consistent finding across all of the studies on the prevalence and incidence of depression is that it is approximately two fold more common among women than men. The average age of onset for unipolar depression falls between the ages of 30 to 35 years. Race and ethnicity are known to influence the clinical presentation of depression, however, studies have shown that if social class, education and residency are controlled, the prevalence of depression did not show

Correspondence: Dr. Saraswati Dhungana, Department of Psychiatry and Mental Health, Maharajgunj Medical Campus Tribhuvan University Teaching Hospital, Kathmandu, Nepal. Email: iomsaras@gmail. com, Phone: +977-9849207669. 
much variation based on cultural factors alone. ${ }^{2}$ Marital status has quite a complex relationship with depression. Depression is most frequent among divorced, separated or widowed individuals. Single women have lower rates of depression than married women do, but the opposite is true for men. ${ }^{2}$ Although the relationship between depression and low social class is well- documented, most studies found only a weak correlation between depressive disorder and socioeconomic status. Depression is seen to more frequent among residents of urban communities than in their rural counterparts.

\section{METHODS}

This was a cross-sectional study conducted within a six-month period. The study population comprised of seventy patients aged more than fifteen years selected by simple random sampling technique who attended the Psychiatry Outpatient Department of Tribhuvan University Teaching Hospital and were diagnosed with first episode depression. Informed consent was taken from the patients and their relatives when they were not able to provide consent because of disease severity. Patients with substance use, other psychiatric diagnoses as psychotic illness, medical comorbidities like hypertension and diabetes, and patients who were pregnant were excluded.

A self-designed semi structured proforma was developed to obtain the socio-demographic characteristics of the study population. It consisted of age, sex, place of residence, educational status, religion, caste, marital status, occupation, type of family, and socioeconomic status.

The diagnosis of depression and its grading as mild, moderate and severe was done on the basis of International Classification of Diseases-10 Diagnostic Criteria for Research (ICD-10 DCR) developed by the division of Mental Health of the World Health Organization. Data were analyzed using SPSS version 16 (Chicago, Illinois, USA). Descriptive analysis was performed, and mean, median, and range were calculated. The data were explained as mean \pm standard deviation (SD) wherever suitable.

\section{RESULTS}

\section{Depression and age}

Mean and SD of age of patients was $30.30 \pm 9.75$ years, range: $15-58$ years. Figure 1 shows the distribution of the respondents on the basis of age group. Majority of the cases were of age group 25-35 (32.9\%) years followed by $15-25$ (31.4\%) years. Age group 35- 45 were $(25.7 \%)$. While there were only two cases in the age group 55- $65(2.9 \%)$, five respondents were in the age group $45-55(7.1 \%)$.

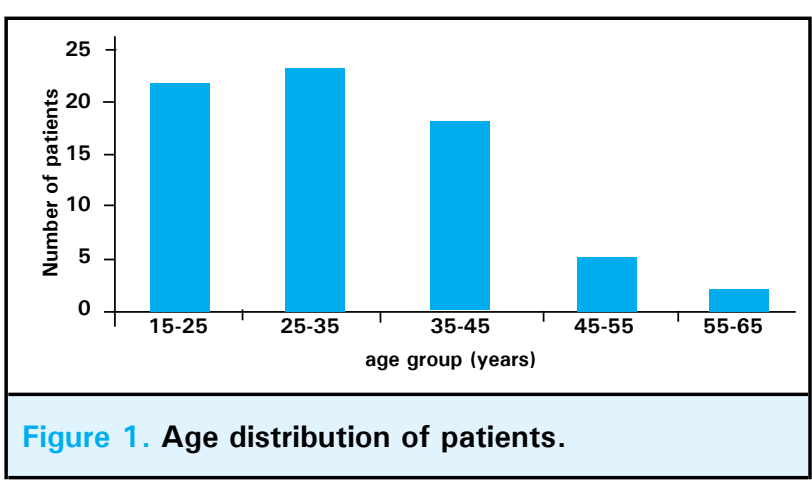

\section{Depression and gender}

Total number of males were 21 (30\%), while females were $49(70 \%)$

\section{Depression and educational status}

Data shows that maximum number of respondents $(31.4 \%, n=22)$ had attained secondary school while $21.4 \% \quad(n=15) \quad$ were university students.Table 1 Twelvepatients $(17.1 \%)$ had studied upto higher secondary level and 7 patients (10\%) had attained upto primary level education while 14 patients (20\%) were illiterate.

\begin{tabular}{|lll|}
\hline $\begin{array}{l}\text { Table 1. Distribution on the basis of educational } \\
\text { status. }\end{array}$ & \\
\hline Educational Status & Number & $\%$ \\
Illiterate & 14 & 20.0 \\
Primary & 7 & 10.0 \\
Secondary & 22 & 31.4 \\
Higher Secondary & 12 & 17.1 \\
University & 15 & 21.4 \\
Total & 70 & $100.0 \%$ \\
\hline
\end{tabular}

\section{Depression and residence}

Thirty four patients $(48.6 \%)$ came from Kathmandu valley while the remaining 36 patients (51.4\%) were from outside the Kathmandu (Table 2).

\begin{tabular}{|c|c|c|}
\hline Address & Number & $\%$ \\
\hline Valley & 34 & $48.6 \%$ \\
\hline Outside valley & 36 & $51.4 \%$ \\
\hline Total & 70 & $100.0 \%$ \\
\hline
\end{tabular}

Depression and marital status

It shows that 45 patients $(64.3 \%)$ were married, 20 
Dhungana et al. Socio-Demographic Correlates in Patients with First Episode Depression in a Tertiary Hospital

patients $(28.6 \%)$ were single and five patients $(7.1 \%)$ were separated. No cases of widow/ widower were found (Table 3).

Table 3. Distribution on the basis of marital status.

\begin{tabular}{|lll|}
\hline Marital Status & Number & $\%$ \\
Single & 20 & 28.6 \\
Married & 45 & 64.3 \\
Separated & 5 & 7.1 \\
Total & 70 & 100.0 \\
\hline
\end{tabular}

\section{Depression and religion}

Most of them were Hindus $(n=61,87.1 \%)$, while 5 $(7.1 \%)$ were Buddhists, $3(4.3 \%)$ were Christians and $1(1.4 \%)$ belonged to others (Kiratis) (Table 4$)$.

\begin{tabular}{|lll|}
\hline \multicolumn{3}{|l|}{ Table 4. Distribution on the basis of religion. } \\
\hline Religion & Number & $\%$ \\
Hindu & 61 & 87.1 \\
Buddhist & 5 & 7.1 \\
Christian & 3 & 4.3 \\
Others & 1 & 1.4 \\
Total & 70 & 100.0 \\
\hline
\end{tabular}

\section{Depression and caste}

Thirty seven $(52.9 \%)$ of them were Brahmins, 11 $(15.7 \%)$ of them were Khetriyas, four $(5.7 \%)$ were Newars, 13 (18.6\%) were Mongolians while others ( Dalits) were five in number $(7.1 \%)$ (Table 5$)$.

\begin{tabular}{|lll|}
\hline \multicolumn{3}{|l|}{ Table 5. Distribution on the basis of caste. } \\
\hline Caste & Number & $\%$ \\
Brahmin & 37 & 52.9 \\
Kshetriya & 11 & 15.7 \\
Newar & 4 & 5.7 \\
Mongolian & 13 & 18.6 \\
Others & 5 & 7.1 \\
Total & 70 & 100.0 \\
\hline
\end{tabular}

\section{Depression and occupation}

Most of the respondents were housewives $(n=25$, $35.7 \%)$, followed by students ( $n=14,20 \%)$. Seven $(10 \%)$ were unemployed during the time of presentaion, $5(7.1 \%)$ were involved in some kind of business, 2 (2.9\%) were engaged in agriculture, 11 (15.7\%) were service holders and six (8.6\%) belonged to others such as driver, shoemaker, carpenter and restaurant dancer (Table 6).

\begin{tabular}{|lll|}
\hline \multicolumn{3}{|l|}{ Table 6. Distribution on the basis of occupation. } \\
\hline Occupation & Number & $\%$ \\
Unemployed & 7 & 10.0 \\
Housewife & 25 & 35.7 \\
Agriculture & 2 & 2.9 \\
Service & 11 & 15.7 \\
Business & 5 & 7.1 \\
Student & 14 & 20.0 \\
Other & 6 & 8.6 \\
Total & 70 & 100.0 \\
\hline
\end{tabular}

\section{Depression and family type}

Of the total respondents, more than half $(n=43$, $61.4 \%)$ were from nuclear family, while 16 (22.9\%) cases were from joint family and $11(15.7 \%)$ from extended family (Table 7).

Table 7. Distribution on the basis of type of family

\begin{tabular}{|lll|}
\hline Family & Number & $\%$ \\
Nuclear & 43 & 61.4 \\
Joint & 16 & 22.9 \\
Extended & 11 & 15.7 \\
Total & 70 & 100.0 \\
\hline
\end{tabular}

\section{Depression and socioeconomic status}

Most of the cases ( $n=38,54.3 \%$ ) came from a middle socioeconomic status, while $23(32.9 \%)$ cases were from lower and $9(12.9 \%)$ from an upper socioeconomic status (Table 8 ).

\begin{tabular}{|lll|}
\hline \multicolumn{3}{|l|}{$\begin{array}{l}\text { Table 8. Distribution on the basis of socioeconomic } \\
\text { status. }\end{array}$} \\
\hline Status & Number & $\%$ \\
Lower & 23 & 32.9 \\
Middle & 38 & 54.3 \\
Upper & 9 & 12.9 \\
Total & 70 & 100.0 \\
\hline
\end{tabular}

\section{DISCUSSION}

The data presented here simply attempts to represent a profile of newly depressed patients visiting a tertiary level hospital in Nepal and hence, utmost care should be taken to generalize the findings keeping in view the different methodology and definition parameters used. Majority of community epidemiological studies find that gender, age, and marital status are associated with depression. Consistent with previous findings by other authors ${ }^{2}$ the mean age of presentation of our patients 
was $30 \pm 9.75$ years (range: $15-58$ years). Previous studies $^{3,4}$ have found a twofold to threefold increased risk of major depression in women compared with men and our findings are consistent with these observations.

It is a long-held belief that people from urban set-up are more at risk for depressive illness compared to their remote counterparts owing to job insecurity, increased stress and migration issues. We observed almost equal number of depressed patients from both inside Kathmandu (48.6\%) and outside of it $(51.4 \%)$, in keeping with the upcoming notion that depression is a universal crisis.

The traditional wisdom holds that marital status confers protection against depression, especially in males and that new onset depressions are more common in widow/ widowers, separated and divorced. The proportion of single, married, and separated patients in our study sample was $28.6 \%(n=20), 64.3 \%(n=45)$, and $7.1 \%$ $(n=5)$, respectively and more than half of the patients were married while no cases were found among widow/ widower, which could have confounded the results.

The prevalence of mood disorders does not differ with ethnicity or religion. We observed $52.9 \% \quad(n=37)$ Brahmins, $15.7 \% \quad(n=11) \quad$ Kshetriyas, $5.7 \% \quad(n=4)$ Newars, $18.6 \%(n=13)$ Mongolians, and the remaining $7.1 \%(n=5)$ other categories. Eighty seven percent ( $n=61$ ) of the population comprised of Hindus followed by Buddhists, $7.1 \%(n=5)$, Christians, $4.3 \%(n=3)$, and others, $1.4 \%(n=1)$. The predominance of Brahmins and Hindus in our study could have confounded the results.

Educational status is known to be linked inversely with depression. Many authors have stated that individuals who are less educated and unemployed are at higher risk for depression. ${ }^{5}$ Our study however, showed that majority of depressed patients represented had attained at least higher secondary level of education (31.4\%) followed closely by those with university level education. This observation is consistent with some previous studies who reported that depression is rated to graduate students higher than undergraduates. ${ }^{6}$

We observed majority of the patients were housewives, $35.7 \%(n=25)$, and one in five patients were students, which is consistent with finding from other studies. ${ }^{7}$

Assessment of socioeconomic status was based on the rough guidelines provided by Central Bureau of Statistics, government of Nepal. More than half of the patient sample, $54.3 \%(n=38)$ belonged to middle class followed by lower class, $32.9 \%(n=23)$, and upper class, $12.9 \%(n=9)$. Most authors observed that higher levels of depression symptoms are particularly common among individuals with economic problems and those of lower socioeconomic status..$^{5,8-11}$ Low income has also been shown as a risk factor for depression in Mormon women, ${ }^{12}$ however, our findings are contrary to these studies and it could be because of the varying definitions of lower, middle and upper social class in different studies.

Most studies showed that depression is more common in families with many members. Our findings showed that $61.4 \%(n=43)$ belonged to nuclear family, $22.9 \%$ ( $n=16)$ to joint family and $15.7 \%(n=11)$ to extended family. More than two- thirds of the total respondents belonged to nuclear family in the present study and therefore, they could be represented as having greater number of depressions.

\section{CONCLUSIONS}

Our study concluded that patients with first episode depression were relatively young, predominantly females. Most of them have attained at least secondary level of education; and most belonged to middle class nuclear families. However, these findings are based on a single center outpatient based samples, so generalization to other settings might not be appropriate.

\section{REFERENCES}

1. Ustun TB, Ayuso-Mateos JL, Chaterji S, Mathers C, Murray CJL. Global burden of depressive disorders in the year 2000.British Journal of Psychiatry. 2004;184:386-92.

2. Sadock BJ, Sadock V. Kaplan and Saddock's Comprehensive Textbook of Psychiatry. USA: Lippincott Williams and Wilkins; 2009.
3. Akhtar-Danesh N, Landeen J. Relation between depression and sociodemographic factors. International Journal of Mental Health Systems. 2007;1:4.

4. Kessler RC, Bromet EJ. The Epidemiology ofDepression Across Cultures Annu. Rev. Public. Health. 2013;34:119-38. 
5. McGrath E, Keita GP, Stickland BR, Russo NF. Women and Depression: Risk factors and Treatment Issues. In: Association AP, editor. Washington DC;1990.

6. Jack DC, Ommeren MV. Depression in Nepalese Women: Tradition, Changing Roles, and Public Health Policy. Moghadam VM, editor: Syracuse University Press; 2001.

7. Raju SS, Kumaraswamy N, Mani AJ. Socio-demographic factors of depressive disorders in India: A comparative appraisal. Indian J Psychiat. 1980;22(4):356-60.

8. Belle D. Social ties and Social Support, Lives in stress: Women and depression. Belle D, editor. Beverly Hills: Sage; 1982. 133-44.
9. Brown GW, Bhrolchain MN, Harris T. Social Class and Psychiatric Disturbance among Women in an Urban Population. Sociology. 1975;9(2):225-54.

10. Hirschfeld R, Cross C. Epidemiology of affective disorders: Psychosocial risk factors. Archives of General Psychiatry. 1982;39:35-46.

11. Makosky UP. Sources of stress: Events or conditions? Lives in stress: women and depression. Beverly Hills: Sage; 1982.

12. Spendlove D, West D, Stanish W. Risk factors and the prevalence of depression in Mormon women. Social science and medicine. 1984;18:491-5. 